\title{
Annealing Kinetic Model Using Fast and Slow Metastable Defects for Hydrogenated-Amorphous-Silicon-Based Solar Cells
}

\author{
Seung Yeop Myong \\ Department of Physical Electronics, Tokyo Institute of Technology (TIT), 2-12-1 Ookayama, Meguro-Ku, Tokyo 152-8552, Japan
}

Received 1 February 2007; Accepted 17 April 2007

Recommended by Armin G. Aberle

The two-component kinetic model employing "fast" and "slow" metastable defects for the annealing behaviors in pin-type hydrogenated-amorphous-silicon- (a-Si:H-) based solar cells is simulated using a normalized fill factor. Reported annealing data on pin-type a-Si:H-based solar cells are revisited and fitted using the model to confirm its validity. It is verified that the twocomponent model is suitable for fitting the various experimental phenomena. In addition, the activation energy for annealing of the solar cells depends on the definition of the recovery time. From the thermally activated and high electric field annealing behaviors, the plausible microscopic mechanism on the defect removal process is discussed.

Copyright (c) 2007 Seung Yeop Myong. This is an open access article distributed under the Creative Commons Attribution License, which permits unrestricted use, distribution, and reproduction in any medium, provided the original work is properly cited.

\section{INTRODUCTION}

In recent years, there has been an explosive, worldwide increase in solar module market due to the global warming and oil crisis. Because bulk crystalline silicon (c-Si) modules make up $90 \%$ of products, a severe shortage of $\mathrm{c}-\mathrm{Si}$ wafers has caused an increase in the cost of the bulk c-Si solar modules. Thus, the increased cost of c-Si wafers currently threats the photovoltaic business. Thin-film Si solar modules using hydrogenated-amorphous-silicon- (a-Si:H-) based absorbers, meanwhile, become a promising alternative to the bulk c-Si solar modules, because of their remarkably low consumption of raw Si material $(<1 \%$ of consumption of bulk c-Si modules), large-scale deposition, and lowtemperature production. Furthermore, thin-film Si photovoltaic technology profits from the wide experience base of the display industries [1].

However, the so-called "Staebler-Wronski effect (SWE)" in a-Si:H-based films remains as a major obstacle to the commercialization of thin-film Si solar modules. SWE is the light-induced degradation arising from the photocreation of dangling bonds (DBs) accomplished by the nonradiative recombination of photogenerated electron-hole pairs $[2,3]$. Because it severely limits the conversion efficiency of a-Si:Hbased films, many researchers have investigated SWE during the past 30 years. Despite extensive investigations, there is no consensus on a microscopic mechanism that explains all the experimental phenomena. Similarly, the recovery mechanism for a-Si:H-based solar cells via thermal annealing $[4,5]$ or intense illumination at high temperature with a strong reverse bias [6] is still controversial. The recovery kinetics via thermal annealing is often interpreted by the stretched exponential (SE) kinetics $[7,8]$ wherein defect generation and annealing in a-Si:H-based materials is a dispersive process controlled by one type of metastable defect $[9,10]$. However, several recent reports have provided experimental evidence that a-Si:H-based materials possess "fast" and "slow" metastable defects, and thus the total defect density cannot uniquely determine the state for the a-Si:H-based solar cells [11-14]. Yang and Chen suggested the existence of the fast and slow metastable defects in a-Si:H solar cells via twostep light soaking [11]; the cell subjected to an intense presoaking exhibits a thermal annealing behavior at the initial stage of 1-sun (AM 1.5, $100 \mathrm{~mW} / \mathrm{cm}^{2}$ ) post-soaking, which could be linked to annealing of the fast metastable defects. Since these results are clearly contradictory to the conventional SE kinetic model, the author suggested a new model of recovery kinetics for pin-type a-Si:H-based solar cells employing the two-component (TC) metastable defect states [15]. We selected the fill factor (FF) as a measure of the state 
for the a-Si:H-based solar cells due to the following reasons: (i) FF is sensitive to the quality of the intrinsic absorber (iabsorber); (ii) analytic equations relating FF to the collection length and to the defect density (or electron spin density) have been developed [16, 17]; and (iii) FF is the most degraded parameter against light-soaking in a-Si:H-based solar cells [18] and is less sensitive to the measurement temperature and illumination intensity compared to the open-circuit voltage and short-circuit current [4].

In this work, the TC model is simulated by varying its parameters. The model is also applied to experimental annealing data for the pin-type a-Si:H-based solar cells in order to verify the validity of the TC model. Finally, the microscopic mechanisms for the annealing behaviors of pin-type a-Si:Hbased solar cells are discussed.

\section{MODELING AND SIMULATION}

If uniform $E$ is assumed in i-absorber of pin-type a-Si:Hbased solar cells, FF is governed by the carrier collection length $\left(l_{c}\right)$ :

$$
l_{c}=\mu \tau E=\mu \tau \frac{\left(V_{b i}-V_{a}\right)}{d},
$$

where $\mu$ is the drift mobility, $\tau$ is the ambipolar carrier lifetime of photogenerated carriers, $E$ is the internal electric filed in the i-absorber, $V_{b i}$ is the built-in potential in the solar cell, $V_{a}$ is the biased voltage, and $d$ is the thickness of the i-absorber. Faughnan and Crandall [16] reported the following empirical relation:

$$
\mathrm{FF}=C_{0}+A \log \frac{l_{c}}{d}
$$

with $C_{0}=0.39$ and $A=0.30$ [17].

Because $\tau$ is reciprocally proportional to the defect density in the i-absorber $(N)$, if $\mu$ is assumed to be constant [17], then

$$
\mathrm{FF} \cong C_{1}-A \log N=C_{1}-K_{1} \ln N
$$

where $C_{1}$ and $K_{1}(=0.30 \log e=0.13)$ are constants.

Accordingly, normalized $\mathrm{FF}\left(\mathrm{FF}_{n}\right)$ can be expressed as

$$
\mathrm{FF}_{n}=\frac{\mathrm{FF}(t)-\mathrm{FF}_{d}}{\mathrm{FF}_{i}-\mathrm{FF}_{d}}=\frac{\ln \left(N / N_{d}\right)}{\ln \left(N_{0} / N_{d}\right)},
$$

where $\mathrm{FF}(t)$ is $\mathrm{FF}$ as a function of time, $\mathrm{FF}_{d}$ is degraded $\mathrm{FF}$ via light soaking, $\mathrm{FF}_{i}$ is initial $\mathrm{FF}$ before light soaking, $N_{d}$ is the defect density in the degraded i-absorber, and $N_{0}$ is the initial defect density in the i-absorber [8].

If it is assumed that the TC model has fast and slow metastable defect states $\left(N_{F}\right.$ and $\left.N_{S}\right)$, then $N=N_{0}+N_{F}+N_{S}$ and $N_{d}=N_{0}+N_{d F}+N_{d s}$. Furthermore, it is assumed that all the defects stem from a common pool of ground states, and there is otherwise no direct communication between the two defect components under fixed annealing conditions. Thus, the system of rate equations for both components can be described as [11]

$$
\begin{aligned}
\frac{d N_{F}}{d t} & =G_{F}\left(N_{T}-N_{F}-N_{S}\right)-A_{F} N_{F}, \\
\frac{d N_{S}}{d t} & =G_{S}\left(N_{T}-N_{F}-N_{S}\right)-A_{S} N_{S},
\end{aligned}
$$

where $N_{T}$ is the total number of states which can be converted into defects, $G_{F}$ and $G_{S}$ are the respective constant defect generation coefficients for the fast and slow metastable defects, and $A_{F}$ and $A_{S}$ are the respective constant defect annealing coefficients for the fast and slow metastable defects. In the case of thermal annealing, we assume that $G_{F}=G_{S}=$ 0 and $A_{F} \gg A_{S}$. Then, the rate equations for $N_{F}$ and $N_{S}$ can be expressed as the following simple first-order approximations:

$$
\begin{aligned}
& \frac{d N_{F}}{d t}=A_{F} N_{F}=-\frac{N_{F}}{\tau_{F}}, \\
& \frac{d N_{S}}{d t}=A_{S} N_{S}=-\frac{N_{S}}{\tau_{S}},
\end{aligned}
$$

where $\tau_{F}$ and $\tau_{S}$ are time constants for the fast and slow metastable defects. Accordingly, $N_{F}$ and $N_{S}$ can be given by

$$
\begin{aligned}
& N_{F}=N_{d F} \exp \left(-\frac{t}{\tau_{F}}\right), \\
& N_{S}=N_{d S} \exp \left(-\frac{t}{\tau_{S}}\right) .
\end{aligned}
$$

After replacement of $N$ and $N_{d}$ by (7), (4) becomes the following kinetic equation:

$$
\mathrm{FF}_{n}=\frac{\ln \left\{n\left[1+\alpha \exp \left(-t / \tau_{F}\right)+\beta \exp \left(-t / \tau_{S}\right)\right]\right\}}{\ln n},
$$

where $n=N_{0} /\left(N_{0}+N_{d F}+N_{d S}\right)=\exp \left[\left(\mathrm{FF}_{d}-\mathrm{FF}_{i}\right) / K_{1}\right]$ from (3), $\alpha$ ( $\left.=N_{d F} / N_{0}\right)$ is the ratio of the photocreated fast metastable defect density to the initial defect density, and $\beta\left(=N_{d S} / N_{0}=1 / n-1-\alpha\right)$ is the photocreated slow metastable defect density to the initial defect density. Therefore, annealing behaviors can be simulated by fitting three independent parameters, $\alpha, \tau_{F}$, and $\tau_{S}$.

Figure 1 provides the simulated results as a function of $t$ using (8). As shown in the figure, four different recovery rates are inspected with $t$ : (i) initial fast rise when $t<\tau_{F}$, (ii) moderate increase when $\tau_{S}<t<\tau_{S}$, (iii) fast increase when $t>\tau_{S}$, and (iv) slow increase in the last tail. Figure 1(a) shows that the increase in $\tau$ increases with an increase in $n$. The rate of the increase decreases with the increase in $n$ when $t<\tau_{S}$. An increase in the fraction of the fast metastable defect $[\alpha /(\alpha+\beta)]$ leads to a fast recovery, as shown in Figure 1(b). It is also found that $\tau_{F}$ is mainly responsible for the initial rise, whereas $\tau_{S}$ affects the last tail as well as the region when $t>\tau_{S}$ (see Figures $1(\mathrm{c})$ and $1(\mathrm{~d})$ ). 


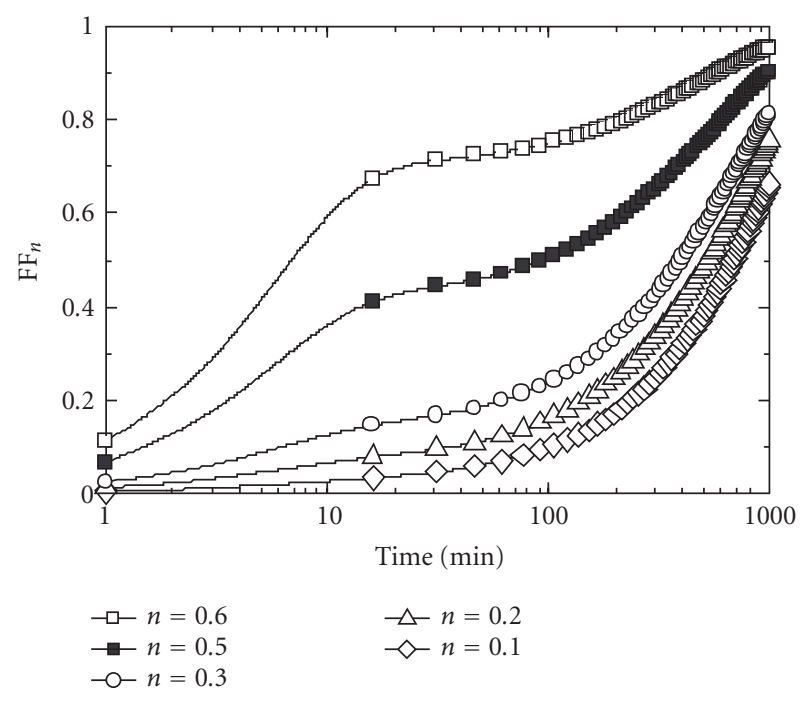

(a)

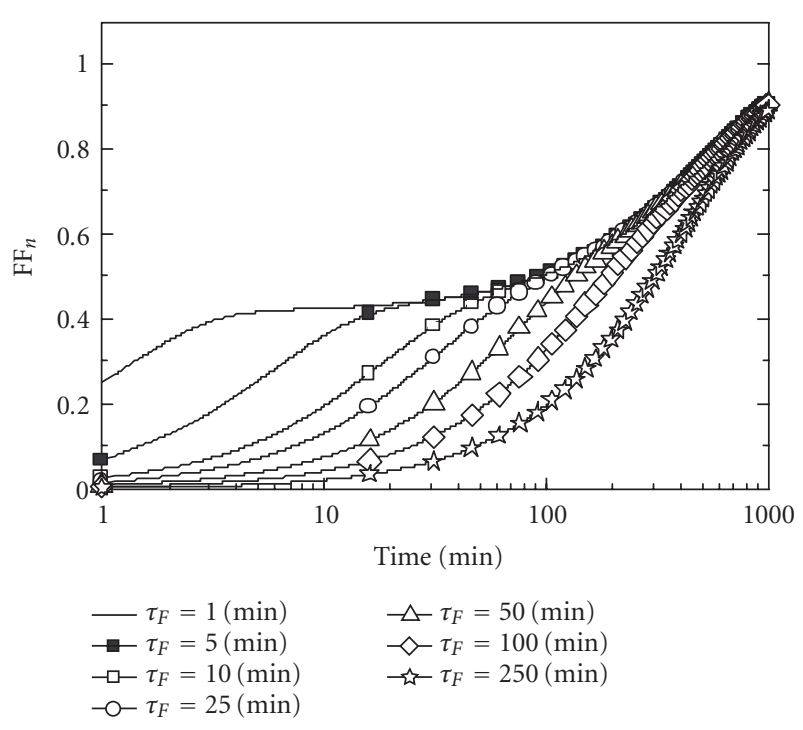

(c)

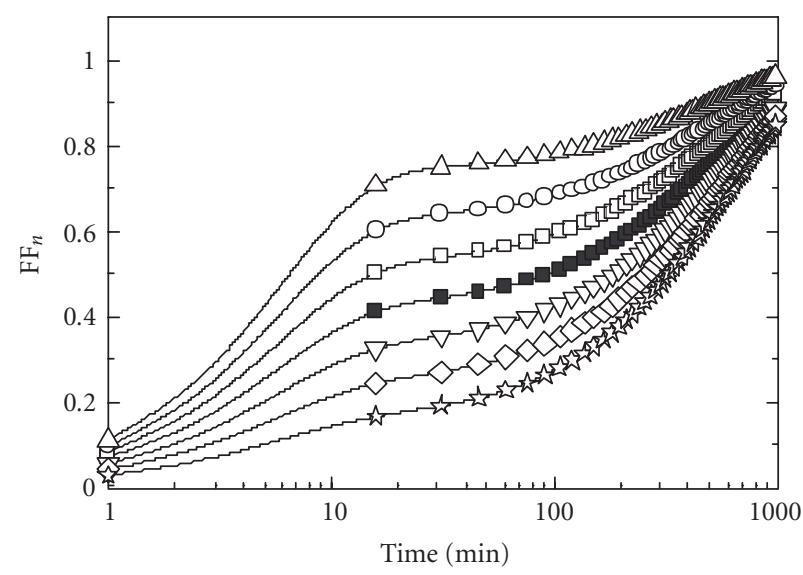

$\triangle \alpha /(\alpha+\beta)=0.8 \quad \rightarrow-\alpha /(\alpha+\beta)=0.4$

$-\alpha-\alpha /(\alpha+\beta)=0.7 \quad \checkmark-\alpha /(\alpha+\beta)=0.3$

$-\square-\alpha /(\alpha+\beta)=0.6$

$\rightarrow \alpha /(\alpha+\beta)=0.5$

(b)

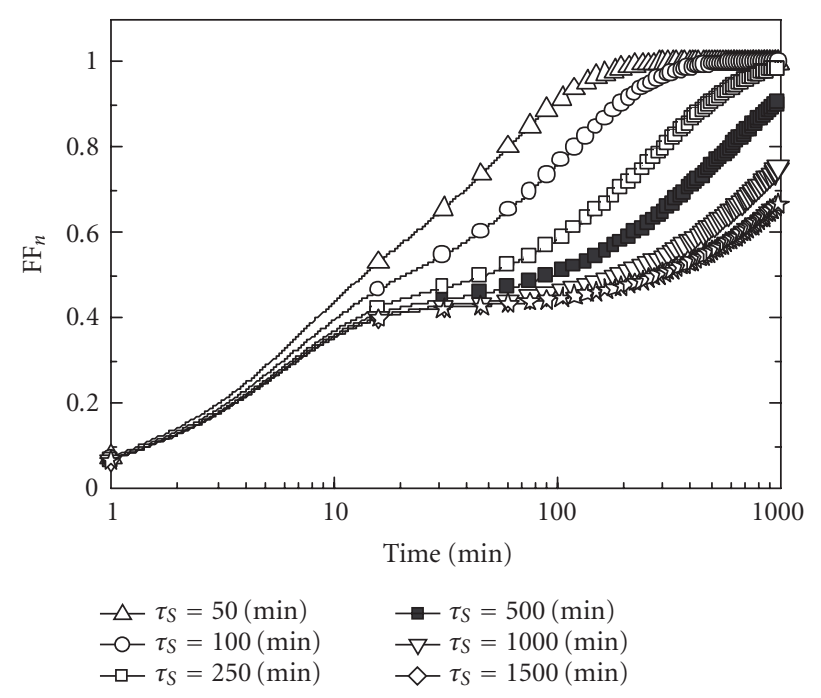

(d)

FIGURE 1: Simulation of annealing behaviors using the TC kinetic model; (a) with variable $n$, and fixed parameters of $\alpha /(\alpha+\beta)=0.5$, $\tau_{F}=5$ minutes, and $\tau_{S}=500$ minutes, (b) with variable $\alpha /(\alpha+\beta)$, and fixed parameters of $n=0.5, \tau_{F}=5$ minutes, and $\tau s=500$ minutes, (c) with variable $\tau_{F}$, and fixed parameters of $n=0.5, \alpha /(\alpha+\beta)=0.5$, and $\tau s=500$ minutes, (d) with variable $\tau_{S}$, and fixed parameters of $n=0.5, \alpha /(\alpha+\beta)=0.5$, and $\tau_{F}=5$ minutes. The symbols are modeled data included to distinguish each other.

\section{RESULTS AND DISCUSSION}

Figure 2 depicts the simulated results using the TC kinetic model for the experimental results with various thermal annealing temperatures $\left(T_{A}\right)$ reported in [4]. The pin-type a$\mathrm{Si}: \mathrm{H}$ solar cell was fabricated via a dc glow discharge technique with a structure of glass/transparent conducting oxide (TCO)/hydrogenated p-type amorphous silicon-carbide (pa-SiC:H)/undiluted i-a-Si:H $(\sim 520 \mathrm{~nm}) / n$-type a-Si:H ( $n$-a$\mathrm{Si}: \mathrm{H}) / \mathrm{Ti} / \mathrm{Ag} . \mathrm{FF}_{i}$ and the initial efficiency are 0.70 and $9 \%$, respectively. In all measurements, the cell was degraded under the 1-sun illumination at $40^{\circ} \mathrm{C}$ for 64 hours. Thus, $\mathrm{FF}_{d}$ is always fixed at $0.55(n=0.32)$. With an increase in $T_{A}, \tau$ declines remarkably.

Figure 3 displays information on evaluated $\tau$ for the simulated data in Figure 2. Here, $\tau_{i}$ denotes the time for FF to recover $i \%$ of its total degradation, that is, $\mathrm{FF}_{i}-\mathrm{FF}_{d}$. As can be seen in Figure 3(a), $\tau_{i}$ is thermally activated, that is, $\tau_{i}=v_{o}^{-1} \exp \left(E_{a} / k T\right)$, where $v_{o}$ is the attempt frequency, $E_{a}$ is the activation energy, $k$ is Boltzmann's constant, and $T$ is the absolute temperature. In [4], Bennett et al. demonstrated that the annealing behavior for their pin-type a-Si:H solar cells could be characterized a unique $E_{a}$ of $1.2 \mathrm{eV}$. They selected $\tau_{50}$ as a measure of $\tau_{i}$. From Figure 3(b), however, it 


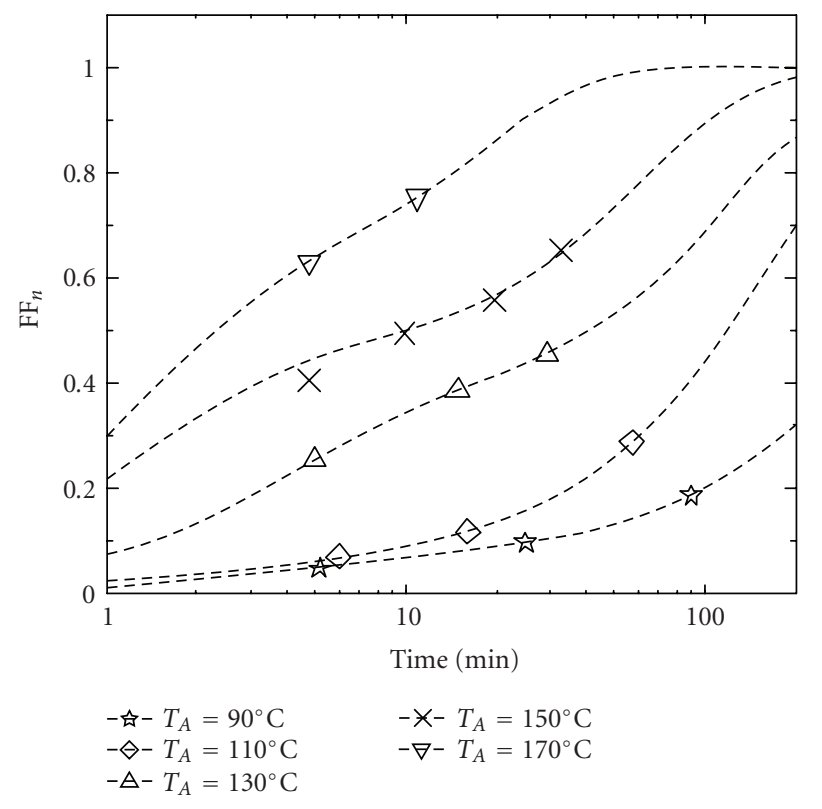

FIgURE 2: Recovery behaviors for the a-Si:H solar cell via thermal annealing as a function of $T_{A}$ (from [4]). The symbols and dotted lines denote experimental data and simulated data using the TC kinetic model, respectively.

should be noted that $E_{a}$ for pin-type a-Si:H-based solar cells depends on $\tau_{i}$ and the TC model present a gradual decrease in $E_{a}$ and $v_{o}$ with an increase in $i$. These phenomena are mainly caused by the existence of the fast and slow metastable defects in the TC model.

Figure 4 compares the simulated results using the TC model for the experimental results reported in [6]. The pin-type solar cell was fabricated at $\sim 200^{\circ} \mathrm{C}$ via a plasmaenhanced chemical vapor deposition (PECVD) technique [5] with a structure of glass $/ \mathrm{SnO}_{2} / \mathrm{p}$-a-SiC: $\mathrm{H} / \mathrm{H}_{2}$-diluted i-a$\mathrm{Si}: \mathrm{H}(\sim 300 \mathrm{~nm}) / n$-a-Si:H/ZnO/Al. At the open-circuit, the cell was degraded under the 50 -sun illumination at $60^{\circ} \mathrm{C}$ for 30 minutes. Hence, $n$ is always fixed at 0.43 by keeping $\mathrm{FF}_{i}$ and $\mathrm{FF}_{d}$ at 0.67 and 0.56 , respectively. Then, the experimental recovery behaviors were inspected under 50-sun illumination with different $V_{a}$. It was found that FF for the pin-type $\mathrm{H}_{2}$-diluted a-Si:H solar cell recovered more rapidly under intense irradiation at $T_{A}=70^{\circ} \mathrm{C}$ with an increase in reversed $V_{a} . \tau_{F}$ and $\tau_{S}$ for the TC model all gradually decrease with the increase in reversed $V_{a}$, thus indicating the high electric filed induced fast recovery. The reduced $\tau$ is mainly due to the decrease in $\tau_{S}$. It is clear that the TC model fits the experimental data well in the initial rise and last tail. Furthermore, the reported different recovery kinetics from identical $\mathrm{FF}_{d}$, which depend on the illumination intensity [11] or temperature [4] during the light-induced degradation, prove that the photocreation of DBs, that is, $N_{d}-N_{0}$, is composed of different kinds of defects.

The author have developed hydrogenated protocrystalline Si (pc-Si:H) multilayer absorbers [18]. The pc-Si:H material is a highly $\mathrm{H}_{2}$-diluted a-Si: $\mathrm{H}$ material existing just
TABLE 1: Fitting parameters used in Figure 5.

\begin{tabular}{l|cccc}
\hline & $n$ & $\alpha /(\alpha+\beta)$ & $\tau_{F}(\min )$ & $\tau_{S}(\min )$ \\
\hline undiluted a-Si:H & 0.39 & 0.82 & 3.7 & 214.6 \\
pc-Si:H multilayer & 0.57 & 0.84 & 3.3 & 59.5 \\
\hline
\end{tabular}

below the threshold of the a-Si:H-to- $\mu \mathrm{c}-\mathrm{Si}: \mathrm{H}$ transition. Using a photoassisted chemical vapor deposition (photo-CVD) technique, we prepared alternately $\mathrm{H}_{2}$-diluted i-pc-Si:H multilayers by modulating the mass flow control of the hydrogen dilution ratio $\left(\mathrm{H}_{2} / \mathrm{SiH}_{4}\right)$, and thereby i-pc-Si: $\mathrm{H}$ has the repeatedly layered structure of low $\mathrm{H}_{2}$-diluted a-Si:H sublayers and highly $\mathrm{H}_{2}$-diluted sublayers. The highly $\mathrm{H}_{2}$-diluted sublayers possess isolated nanosized $\mathrm{Si}$ (nc-Si) grains embedded in a-Si:H matrix [19]. The i-pc-Si:H multilayers exhibit a fast light-induced metastability with a low degradation. Consequently, highly stabilized solar cells (stabilized efficiency $=9.0 \%$ ) were achieved without using any back reflector $[20,21]$. The pc-Si:H multilayer solar cells exhibit a very fast annealing behavior during 1-sun post-soaking, compared to a-Si:H solar cells [22], which is the clear evidence of the two-component metastable defects in the pc$\mathrm{Si}: \mathrm{H}$ multilayers. Figure 5 shows the fitted results using the TC model for the experimental recovery behaviors in an undiluted a-Si:H solar cell and a pc-Si:H multilayer solar cell in [8]. The pin-type solar cells were fabricated at $250^{\circ} \mathrm{C}$ via a photoassisted chemical vapor deposition (photo-CVD) technique with a structure of glass $/ \mathrm{SnO}_{2} / \mathrm{p}-\mathrm{a}-\mathrm{SiC}: \mathrm{H} / \mathrm{p}-\mu \mathrm{c}-\mathrm{Si}: \mathrm{H} / \mathrm{i}-$ absorber $(\sim 550 \mathrm{~nm}) / n$ - $\mu \mathrm{c}-\mathrm{Si}: \mathrm{H} / \mathrm{Al}$. The initial efficiency for the undiluted a-Si:H and pc-Si:H multilayer solar cells are 10.6 and $8.9 \%$, and $\mathrm{FF}_{i}$ values are 0.73 and 0.69 , respectively. The solar cells were degraded under the 1-sun illumination at $48^{\circ} \mathrm{C}$ for 20 hours. After light soaking, the pc-Si:H multilayer cell stabilized with $n=0.57$, while the undiluted a-Si:H cell is still in degrading state with $n=0.39$. The fitting parameters of the cells are listed in Table 1. Thermal annealing is performed in a vacuum chamber. The pc-Si:H multilayer cell exhibits the rapider recovery than the undiluted a-Si:H cell.

From the fast metastability and annealing behaviors of pc-Si:H multilayer solar cells, the vertically regular distribution of the isolated nc-Si grains [21] and the improved medium-range-order in the a-Si:H matrix [23] are considered to localize the photocreation near the grain boundary regions [19], and thereby suppress the photocreation of slow metastable defects in the pc-Si:H multilayers. From the visible photoluminescence (PL) peak measured at room temperature, the isolated nc-Si grains tend to act as radiative recombination centers of captured carriers, which may contribute to the good stability [14].

Because the pc-Si:H multilayer has a slightly wider optical band gap (effective band gap $>1.7 \mathrm{eV}$ ) than conventional a-Si:H layers $(\sim 1.7 \mathrm{eV})$, the pc-Si:H multilayer solar cell is promising as a top cell for a high-efficiency tandem cell [23]. The pc-Si:H multilayer/ $\mu c-S i: H(\sim 1.1 \mathrm{eV})$ double-junction tandem structure opened the possibility of a significantly 


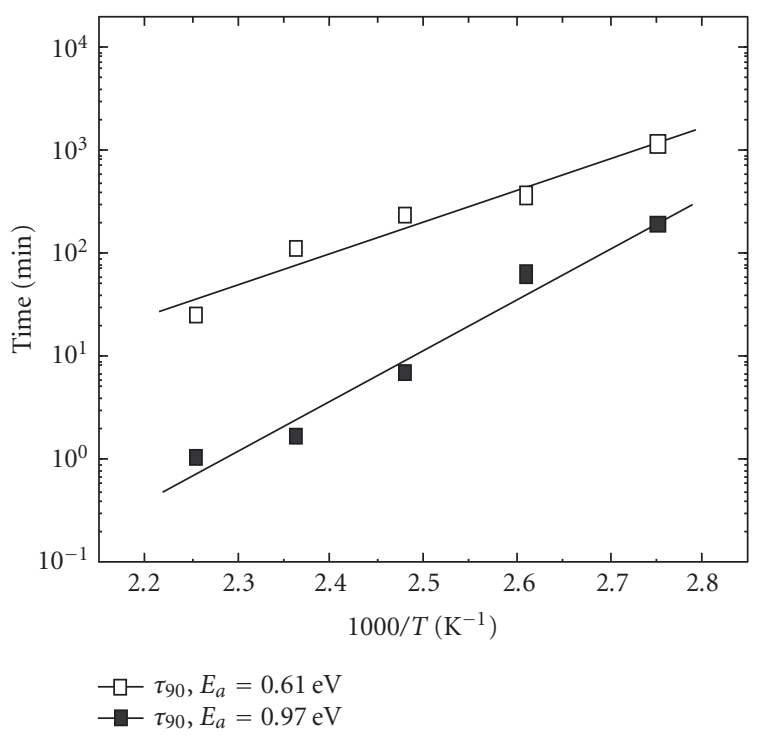

(a)

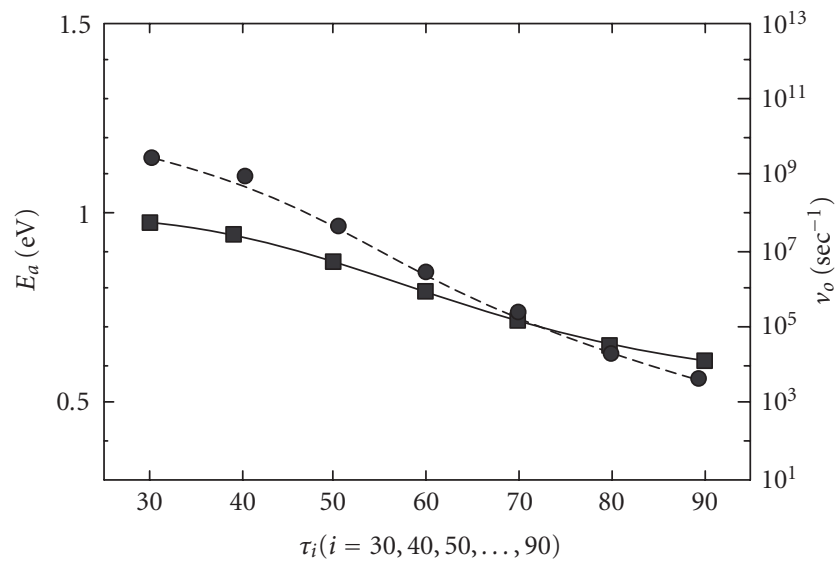

$\rightarrow-E_{a}$

(b)

FIGURE 3: Information on evaluated $\tau$ for the simulated data in Figure 2; (a) Arrhenius plot for $\tau_{30}$ and $\tau_{90}$. The calculated values of $E_{a}$ for $\tau_{30}$ and $\tau_{90}$ are provided. (b) $E_{a}$ and $v_{o}$ versus $\tau_{i}$.

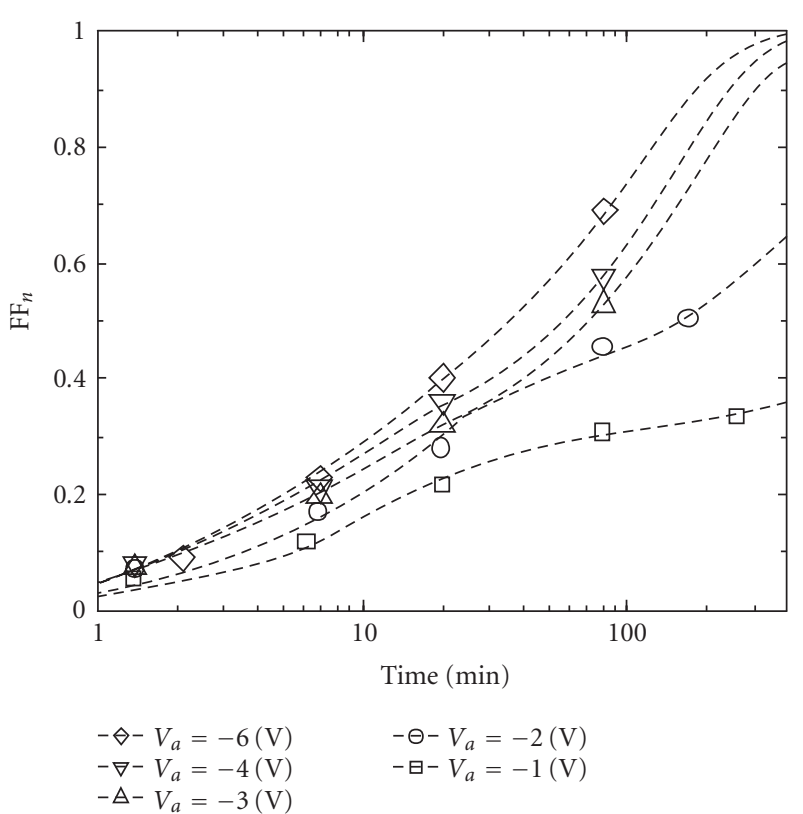

(a)

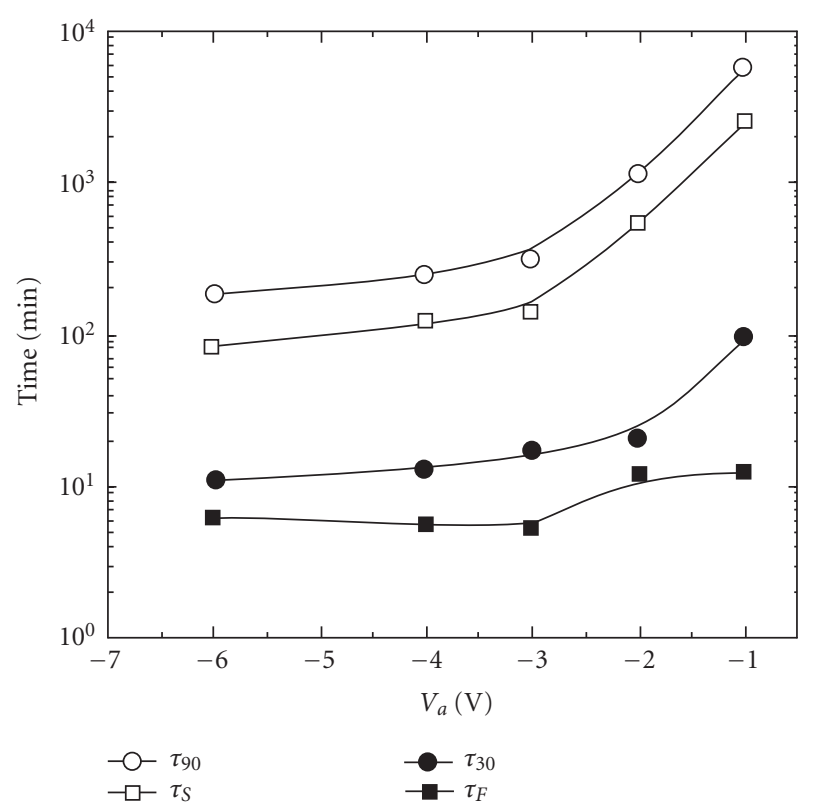

(b)

FIGURE 4: Annealing for the $\mathrm{H}_{2}$-diluted a-Si:H solar cell under intense (50-sun) illumination at $T_{A}=70^{\circ} \mathrm{C}$ (from [6]); (a) recovery behaviors with different $V_{a}$ and (b) $\tau_{30}$ and $\tau_{90}$ versus $V_{a}$. The symbols and dotted lines denote experimental data and simulated data using the TC kinetic model, respectively.

high-stabilized efficiency due to a low-degradation ratio [24].

The photocreation of DBs in an a-Si:H matrix can occur with a value of $E_{a}$ [25] that is lower than $E_{a}$ for light-induced long range $\mathrm{H}$ diffusion $(0.9 \mathrm{eV})$ [26]. Hence, the breaking of strong $\mathrm{Si}-\mathrm{H}$ bonds $(\sim 3 \mathrm{eV})$, proposed by Branz in the hy- drogen collision model [27], cannot be easily accomplished by the nonradiative recombination of electron-hole pairs. Instead, the breaking of weak $\mathrm{Si}-\mathrm{Si}$ bonds due to nonradiative recombination of electron-hole pairs is considered today as a plausible origin of SWE $[28,29]$. Recently, Powell et al. [29] proposed the creation of two metastable HSiDB (complex of 


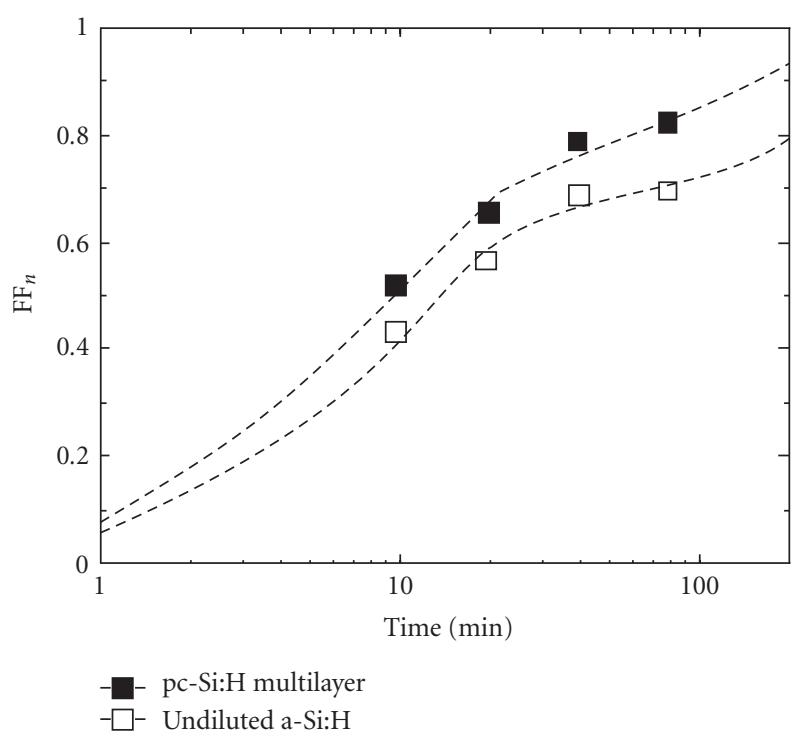

(a)

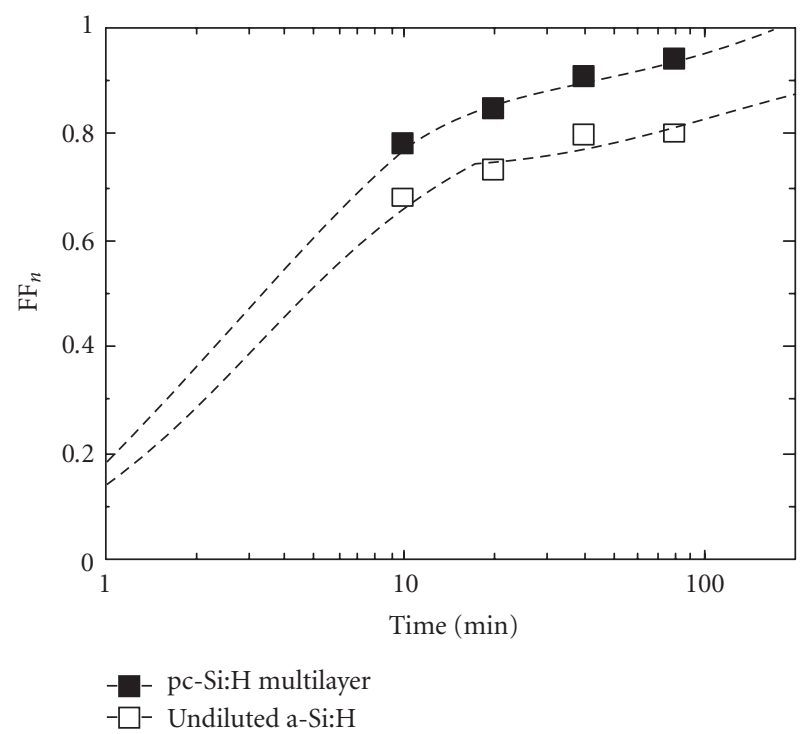

(b)

FIGURE 5: Comparison of the recovery behavior via thermal annealing between the undiluted a-Si:H and pc-Si:H multilayer solar cells (from [8]); (a) $T_{A}=108^{\circ} \mathrm{C}$ and (b) $T_{A}=133^{\circ} \mathrm{C}$. The symbols and dotted lines denote experimental data and simulated data using the TC kinetic model, respectively.

a DB and an $\mathrm{Si}-\mathrm{H}$ bond, where $\mathrm{H}$ locates in a tetrahedrallike site $\left(T_{d}\right)$, not a bond-centered site) defects; an $\mathrm{H}$ atom from a neighboring doubly hydrogenated weak $\mathrm{Si}-\mathrm{Si}$ bond (HSiSiH) switches to a $T_{d}$ site of the broken $\mathrm{Si}-\mathrm{Si}$ bond and the other $\mathrm{H}$ from $\mathrm{HSiSiH}$ is also located in the energetically suitable $T_{d}$ site. This model is reasonable because the spatial separation between $\mathrm{H}$ in the $T_{d}$ site and $\mathrm{DB}$ is in agreement with the observed values of 4-5 $\AA$ by electron spin resonance (ESR) measurements [30]. On the other hand, it has been reported that annealing of DBs in a-Si:H films, which are photocreated at moderate temperature, has a similar value of $E_{a}$ (1.1-1.2 eV) [31] to that for long range $\mathrm{H}$ diffusion $(1.5 \mathrm{eV})$ [32]. This supports the supposition that long range $\mathrm{H}$ diffusion plays an important role in annealing of metastable defects. Thus, the hydrogen collision model is valid in the case of annealing and $E_{a}$ can be interpreted as the energy for the thermal emission of $\mathrm{H}$ from a $T_{d}$ site. In addition, $v_{o}$ corresponds with the phonon frequency of $\mathrm{Si}-\mathrm{H}$ bonds [29] and with the thermal emission process. However, it is difficult to define unique $E_{a}$ and $v_{o}$ for $\tau$, because it varies with $\tau_{i}$ (see Figure 3(b)). Nevertheless, $E$ in a solar cell is expected to lower the energy barrier for long range $\mathrm{H}$ diffusion [6]. From Figure 4, it can be concluded that the intense illumination at a high temperature also thermally emits mobile $\mathrm{H}$ by breaking $\mathrm{Si}-\mathrm{H}$ bonds, and leads to high electric field induced annealing for the solar cells.

In the previous report [15], the author proposed the following mechanism for the recovery kinetics in pin-type a-Si:H-based solar cells based on the TC model: (i) mobile $\mathrm{H}$ is thermally emitted from a metastable HSiDB defect by breaking the $\mathrm{Si}-\mathrm{H}$ bond. As reflected in Figure 2, the elevated $T_{A}$ increases the thermal emission rate of mo- bile $\mathrm{H}$ [32]; (ii) emission of bonded $\mathrm{H}$ is followed by weak $\mathrm{Si}-\mathrm{Si}$ bond reconstruction. Meanwhile, mobile $\mathrm{H}$ migrates through the lattice $[33,34]$ and is subsequently captured at another weak $\mathrm{Si}-\mathrm{Si}$ bond, which eventually forms an HSiDB defect. It should be noted that $E$ in $\mathrm{i}$-absorber assists the migration of mobile $\mathrm{H}$ to a shallower site, which is reflected in Figure 4; and (iii) thermal emission and recapturing processes of mobile $\mathrm{H}$ proceed until it is captured at the DB site of a metastable HSiDB defect, resulting in the annealing of two defects. Consequently, for the annealing process to reform the a-Si:H matrix, a considerable energy is required and many $\mathrm{H}$ atoms are involved. However, an internal field formed in solar cells can reduce the required energy for the annealing process. It should be noted that the classification between the fast and slow metastable defects is mainly determined by their activation energy and capture cross-section [14]. This classification is only relative and is dependent on the annealing conditions, that is, elevated $T_{A}$ or $V_{a}$ can increase $\alpha$.

\section{CONCLUSIONS}

The author simulated the TC model in order to understand the effect of each parameter on the annealing kinetics in pintype a-Si:H-based solar cells. This model displays that $E_{a}$ depends on the definition of the recovery time. It is verified that the TC model fits the various experimental data. Thus, the TC model can be deemed useful for limiting the number of mechanisms responsible for annealing the photocreated defects in a-Si:H. From the thermally activated and high electric field induced nature of annealing behaviors, the plausible microscopic mechanism on the DB defect removal related to the 
thermal emission of mobile $\mathrm{H}$ from $T_{d}$ sites and long range $\mathrm{H}$ diffusion was discussed.

\section{REFERENCES}

[1] A. Shah, P. Torres, R. Tscharner, N. Wyrsch, and H. Keppner, "Photovoltaic technology: the case for thin-film solar cells," Science, vol. 285, no. 5428, pp. 692-698, 1999.

[2] D. L. Staebler and C. R. Wronski, "Reversible conductivity changes in discharge-produced amorphous Si," Applied Physics Letters, vol. 31, no. 4, pp. 292-294, 1977.

[3] D. L. Staebler, R. S. Crandall, and R. Williams, "Stability of $n-i-p$ amorphous silicon solar cells," Applied Physics Letters, vol. 39, no. 9, pp. 733-735, 1981.

[4] M. S. Bennett, J. L. Newton, K. Rajan, and A. Rothwarf, "Kinetic studies of the annealing behavior of $a-\mathrm{Si}: \mathrm{H} p-i-n$ solar cells," Journal of Applied Physics, vol. 62, no. 9, pp. 3968-3975, 1987.

[5] D. E. Carlson and K. Rajan, "The reversal of light-induced degradation in amorphous silicon solar cells by an electric field," Applied Physics Letters, vol. 70, no. 16, pp. 2168-2170, 1997.

[6] D. E. Carlson and K. Rajan, "Evidence for proton motion in the recovery of light-induced degradation in amorphous silicon solar cells," Journal of Applied Physics, vol. 83, no. 3, pp. 1726-1729, 1998.

[7] A. Terakawa, H. Matsunami, S. Kiyama, and S. Tsuda, "Origin of the optical gap dependence of $a$-SiGe solar cell stability," Journal of Applied Physics, vol. 84, no. 8, pp. 4611-4616, 1998.

[8] K. H. Jun, J. D. Ouwens, R. E. I. Schropp, et al., "Low degradation and fast annealing effects of amorphous silicon multilayer processed through alternate hydrogen dilution," Journal of Applied Physics, vol. 88, no. 8, pp. 4881-4888, 2000.

[9] D. Redfield and R. H. Bube, "Reinterpretation of degradation kinetics of amorphous silicon," Applied Physics Letters, vol. 54, no. 11, pp. 1037-1039, 1989.

[10] W. B. Jackson and J. Kakalios, "Evidence for hydrogen motion in annealing of light-induced metastable defects in hydrogenated amorphous silicon," Physical Review B, vol. 37, no. 2, pp. 1020-1023, 1988.

[11] L. Yang and L. Chen, "“Fast" and "slow" metastable defects in hydrogenated amorphous silicon," Applied Physics Letters, vol. 63, no. 3, pp. 400-402, 1993.

[12] J. Pearce, X. Niu, R. Koval, et al., "Contributions of $\mathrm{D}^{0}$ and non- $\mathrm{D}^{0}$ gap states to the kinetics of light induced degradation of amorphous silicon under 1 sun illumination," Materials Research Society Symposium Proceedings, vol. 664, no. A12.3, 2001.

[13] J. M. Pearce, J. Deng, R. W. Collins, and C. R. Wronski, "Lightinduced defect states in hydrogenated amorphous silicon centered around 1.0 and $1.2 \mathrm{eV}$ from the conduction band edge," Applied Physics Letters, vol. 83, no. 18, pp. 3725-3727, 2003.

[14] S. Y. Myong, S. W. Kwon, K. S. Lim, M. Kondo, and M. Konagai, "Inclusion of nanosized silicon grains in hydrogenated protocrystalline silicon multilayers and its relation to stability," Applied Physics Letters, vol. 88, Article ID 083118, 3 pages, 2006.

[15] S. Y. Myong and K. S. Lim, "Modeling of annealing kinetics for hydrogenated-amorphous-silicon-based solar cells using twocomponent metastable defects," Applied Physics Letters, vol. 88, Article ID 243510, 3 pages, 2006.

[16] B. W. Faughnan and R. S. Crandall, "Determination of carrier collection length and prediction of fill factor in amorphous silicon solar cells," Applied Physics Letters, vol. 44, no. 5, pp. 537-539, 1984.

[17] Z. E. Smith, S. Wagner, and B. W. Faughann, "Carrier lifetime model for the optical degradation of amorphous silicon solar cells," Applied Physics Letters, vol. 46, no. 11, pp. 1078-1080, 1985.

[18] S. Y. Myong, S. W. Kwon, K. S. Lim, and M. Konagai, "Highly stabilized protocrystalline silicon multilayer solar cell using a silicon-carbide double p-layer structure," Solar Energy Materials and Solar Cells, vol. 85, no. 1, pp. 133-140, 2005.

[19] S. Y. Myong, "Recent progress in inorganic solar cells using quantum structures," Recent Patents on Nanotechnology, vol. 1, no. 1, pp. 67-73, 2007.

[20] S. Y. Myong, K. S. Lim, and J. M. Pearce, "Double amorphous silicon-carbide $p$-layer structures producing highly stabilized pin-type protocrystalline silicon multilayer solar cells," Applied Physics Letters, vol. 87, Article ID 193509, 3 pages, 2005.

[21] S. Y. Myong, S. W. Kwon, M. Kondo, M. Konagai, and K. S. Lim, "Development of a rapidly stabilized protocrystalline silicon multilayer solar cell," Semiconductor Science and Technology, vol. 21, no. 2, pp. L11-L15, 2006.

[22] S. W. Kwon, J. Y. Ahn, S. Y. Myong, and K. S. Lim, "Alternately hydrogen diluted amorphous silicon multilayer solar cell with low degradation rate under 10\%," in Proceedings of the 17th European Photovoltaic Solar Energy Conference and Exhibition, pp. 3015-3018, Munich, Germany, October 2001.

[23] S. Y. Myong, S. W. Kwon, J. H. Kwak, K. S. Lim, J. M. Pearce, and M. Konagai, "Good stability of protocrystalline silicon multilayer solar cells against light irradiation originating from vertically regular distribution of isolated nano-sized silicon grains," in Proceedings of the 4th IEEE World Conference on Photovoltaic Energy Conversion, vol. 2, pp. 1584-1587, IEEE, Waikoloa, Hawaii, USA, May 2006.

[24] J. H. Kwak, Development of high efficiency, low degradation tandem solar cells using protocrystalline silicon (pc-Si:H) multilayer, Ph.D. thesis, Korea Advanced Institute of Science and Technology, Taejon, Korea, 2007.

[25] P. Stradins and H. Fritzsche, "Photoinduced creation of metastable defects in $a$-Si:H at low-temperatures and their effect on the photoconductivity," Philosophy Magazine B, vol. 69, no. 1, pp. 121-139, 1994.

[26] P. V. Santos, N. M. Johnson, and R. A. Street, "Light-enhanced hydrogen motion in a-Si:H," Physical Review Letter, vol. 67, no. 19 , pp. 2686-2689, 1991.

[27] H. M. Branz, "Hydrogen collision model: quantitative description of metastability in amorphous silicon," Physical Review B, vol. 59, no. 8, pp. 5498-5512, 1999.

[28] V. Nádaždy and M. Zeman, "Origin of charged gap states in $a$ Si:H and their evolution during light soaking," Physical Review $B$, vol. 69, Article ID 165213, 6 pages, 2004.

[29] M. J. Powell, S. C. Deane, and R. B. Wehrspohn, "Microscopic mechanisms for creation and removal of metastable dangling bonds in hydrogenated amorphous silicon," Physical Review B, vol. 66, no. 15, Article ID 155212, 11 pages, 2002.

[30] J. Isoya, S. Yamasaki, H. Okushi, A. Matsuda, and K. Tanaka, "Electron-spin-echo envelope-modulation study of the distance between dangling bonds and hydrogen atoms in hydrogenated amorphous silicon," Physical Review B, vol. 47, no. 12, pp. 7013-7024, 1993.

[31] M. Stutzmann, W. B. Jackson, and C. C. Tsai, "Light-induced metastable defects in hydrogenated amorphous silicon: a systematic study," Physical Review B, vol. 32, no. 1, pp. 23-47, 1985. 
[32] H. M. Branz, "Hydrogen diffusion and mobile hydrogen in amorphous silicon," Physical Review B, vol. 60, no. 11, pp. 7725-7727, 1999.

[33] H. M. Branz, Y. Xu, S. Heck, and W. Gao, "Improved stability of hydrogenated amorphous-silicon photosensitivity by ultraviolet illumination," Applied Physics Letters, vol. 81, no. 18, pp. 3353-3355, 2002.

[34] S. Y. Myong, S. S. Kim, and K. S. Lim, "In situ ultraviolet treatment in an Ar ambient upon $p$-type hydrogenated amorphous silicon-carbide windows of hydrogenated amorphous silicon based solar cells," Applied Physics Letters, vol. 84, no. 26, pp. 5416-5418, 2004. 

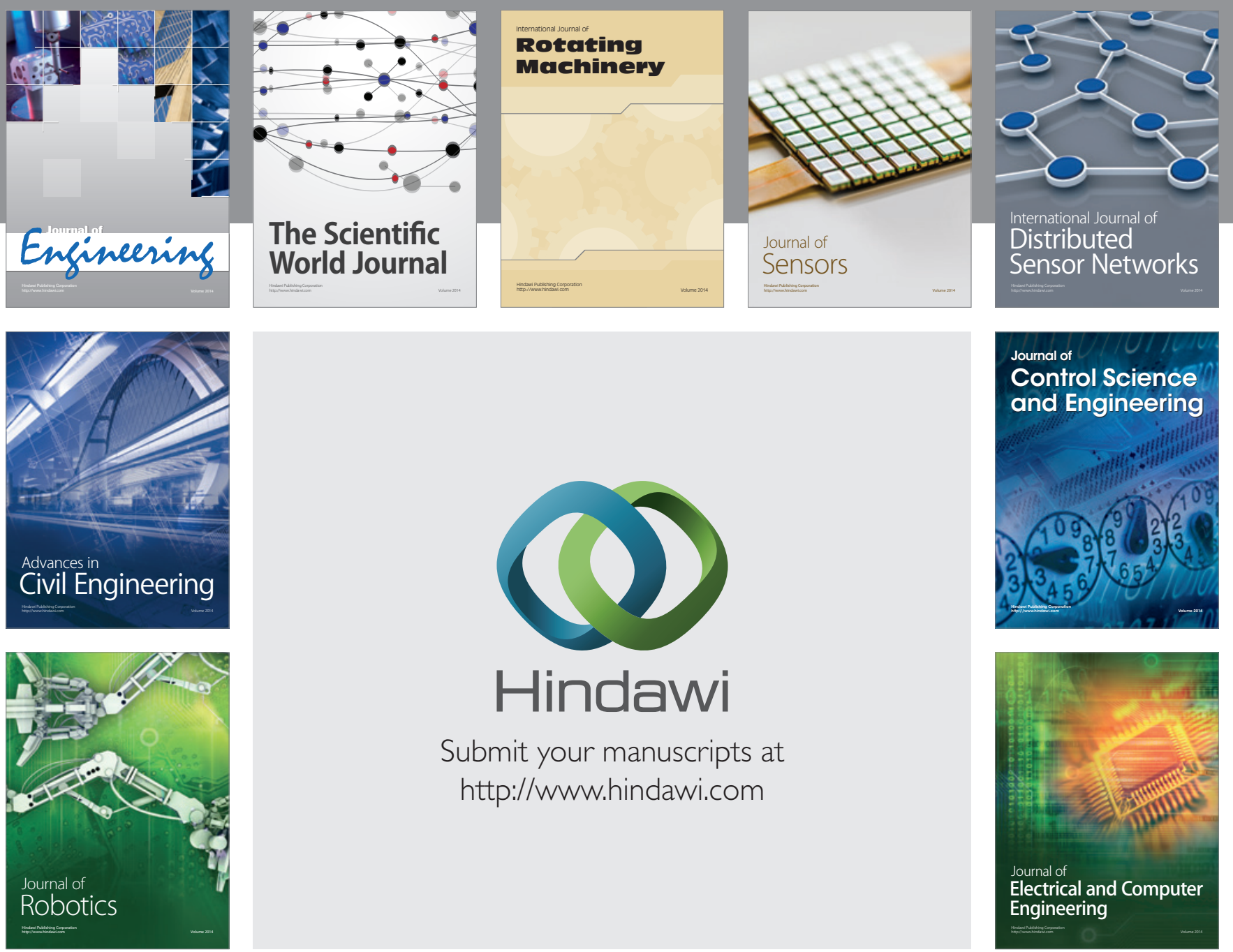

Submit your manuscripts at

http://www.hindawi.com
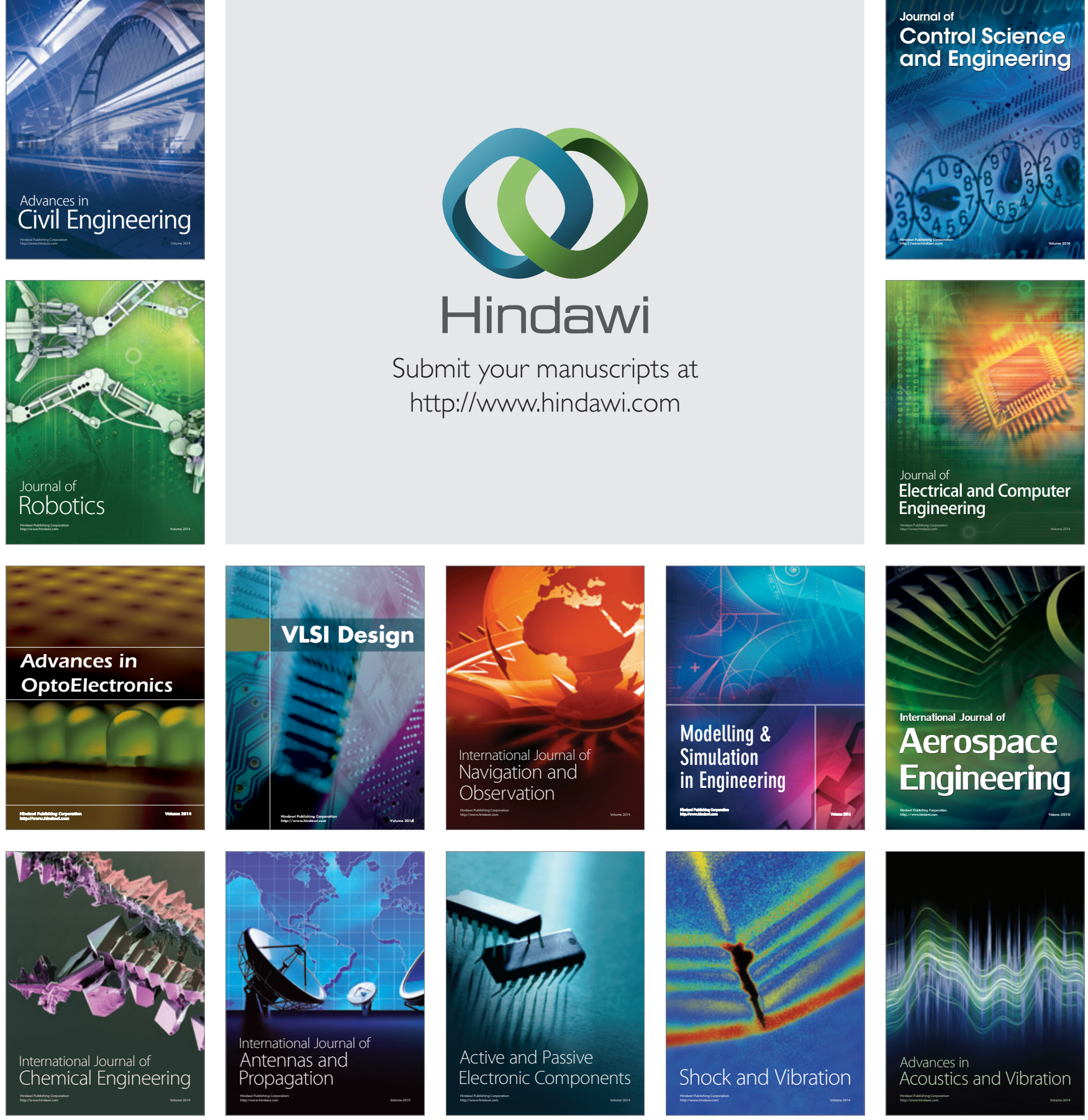